\title{
Early Event Detection and Discontinuation of the Culprit Drug Increases the Rate of Survival in Severe Cutaneous Adverse Drug Reactions: A Multi-Center Study in Bangladesh
}

\author{
Jahidul Hasan ${ }^{1}$, Ruhul Hassan Joarder ${ }^{2}$, Raihan Rabbani ${ }^{3}$, \\ Sitesh C. Bachar ${ }^{4}$
}

\author{
${ }^{1}$ Department of Pharmacy, Square Hospitals Ltd., Dhaka, Bangladesh \\ ${ }^{2}$ General Surgery, Department of Medical Services, Square Hospitals Ltd., Dhaka, Bangladesh \\ ${ }^{3}$ Internal Medicine and ICU, Department of Medical Services, Square Hospitals Ltd., Dhaka, Bangladesh \\ ${ }^{4}$ Department of Pharmacy, University of Dhaka, Bangladesh
}

\begin{abstract}
Adverse drug reactions are completely unwanted drug reactions derived from self-medications and among those unpleasant reactions, severe cutaneous adverse drug reactions like, Stevens-Johnson Syndrome, Toxic Epidermal Necrolysis, Acute Generalized Exanthematous Pustolosis and Drug Reaction with Eosinophilia and Systemic Symptoms, are mostly life threatening harms, globally. The main objective of this study was to find out the impact of early detection of the adverse drug events and consequently prompt withdrawn of the suspected culprit drugs in the ultimate survival rate among the patients experienced with these types of unwelcome life threatening events in Bangladesh. Here, we found that antibiotics were accounted for most adverse drug reactions $(81.13 \%$, $\mathrm{n}=53$ ) including serious reactions. This study also showed that if the adverse drug event is possibly detected with in the first 48 hours then, $72.73 \%(n=11)$ patients were survived from severe cutaneous adverse drug reactions, where as if delayed than 48 hours, only $20 \%(n=5)$ patients were survived. Similarly, $77.77 \%(n=9)$ patients were survived after the proper treatment when suspected culprit drugs were discontinued within first 48 hours and late discontinuation resulted in only $28.57 \%(n=7)$ survival rate among these patients. So, prompt response through early event-detection and discontinuation of the culprit drug, to a serious cutaneous adverse drug reaction can tremendously save life by providing early necessary management and required treatment.
\end{abstract}

Keywords: Adverse Drug Event, Severe Cutaneous Adverse Drug Reactions, Antibiotics, Stevens-Johnson Syndrome, Toxic Epidermal Necrolysis

\section{Introduction}

An adverse drug event (ADE) can be defined as an injury resulting from medical intervention related to a drug (Kohn et al. 2000). An adverse drug reaction (ADR) is a medication-induced injury. ADR can also be defined as a noxious, unpleasant or unwanted reaction resulting from a medicinal intervention at a regular dose used in human in order to prophylaxis, diagnosis or therapy (Aronson et al. 2005; World health organization, 2003). ADRs are the fourth among the six leading causes of death in USA and $6.9 \%$ of total admitted patients in Indian hospitals are due to ADRs (Chowdhury et al. 2016). ADRs can be broadly classified into two groups- type A (predictable reactions, usually dose-dependent) and type B (unpredictable or idiosyncratic, and not dosedependent). Other short classifications are type $\mathrm{C}$ (chronic, depends on dose and time); type D (delayed reaction); type $\mathrm{E}$ (end of use reactions that cover withdrawals) and type $\mathrm{F}$ (failure of therapy) (Coleman et al. 2016).

In late $20^{\text {th }}$ and early $21^{\text {st }}$ century, in USA and UK, the seminal research mentioned that ADRs are most common in the patients on home medications, during the hospitalization and even in hospital discharged patients (Coleman et al. 2016). Both the ADE and ADR are the practicing components of pharmacovigilance (PV) and it can be defined as 'the science and activities relating to the detection, assessment, understanding and prevention of adverse events or any other drug-related problem' (World health organization, 2002).

Multiple studies found that hospital-based ADR reports are more commonly associated with ADR- 
related deaths and it account for 2.5 to $18 \%$ of total deaths among the hospitalized patients (Buajordet et al. 2001; Ebbesen et al. 2001; Juntti-Patinen et al. 2002; Davies et al. 2009; Mehta et al. 2008). Severe adverse drug reactions like, Stevens-Johnson Syndrome (SJS), Toxic Epidermal Necrolysis (TEN), Acute Generalized Exanthematous Pustolosis (AGEP) and Drug Reaction with Eosinophilia and Systemic Symptoms (DRESS), also known as Severe Cutaneous Adverse Drug Reactions (SCADRs), are rare incidences but these may be life-threatening events with lethal outcomes and mostly, druginduced (Harr et al. 2010; Teo et al. 2016).

In Bangladesh, the structure of ADR-related data collection system is currently not well organized in both public and private healthcare sectors and there are few local studies show the scenario of the severity of ADRs. So, more ADR-focused studies are required to better understand the country's recent situation in ADR monitoring and drug safety practices. The main aim of this study was to find out the impact of early detection of ADRs with a fast initiative to take the victim under necessary treatment at hospital settings, and the affect of undelayed discontinuation of the culprit drug in severe ADRs in Bangladesh.

\section{Materials and Methods}

All ADRs data of this prospective study were collected from Dhaka-based two tertiary and one secondary level hospital. The study was started in June, 2016 and ended in June, 2018. Every hospital had their own PV setups and they reported their ADRs independently. For the study purpose, all the reported ADRs were accumulated, centrally and then segregated according to the study purpose. ADRs of the ADR-victims, who were experienced with ADEs outside the hospital setups, were considered for this study and no ADE report happened inside the hospital premises was accepted for the study purpose. During those 24 months of study period, PV-focal points of those hospitals were communicated, spontaneously for gathering current ADE-related information. All the data were prospectively collected in different ways- (1) direct conversation with the victims or close relatives of the victims; (2) analysis of the hospitalized internal ADE reports; (3) analysis of the victims' hospital admission notes; (4) communication with the respective doctors and nurses; (5) analysis of the patients' previous medical and medication histories (before and after the sentinel event); (6) analysis of admission notes of previous hospital(s) (if any) and (7) communication with the PV-focal points of the respective hospitals. All the ADRs data were oriented by using Microsoft Office Excel, 2007. Except only the survival and the death data of the ADRs, no treatment paradigm or disease status of the victims followed by ADE, was considered in this study. Severity of the ADRs was determined on the basis of the physicians' clinical diagnostic-declarations.

\section{Results}

During that 18-months period taken for the study, reports of ADRs were generated in different victims with different types of drugs. Total 53 (n) ADRs were found during that selected time and analyzed (Table 1). $43(81.13 \%, n=53)$ reports were found against antibiotics; $3(5.66 \%, \mathrm{n}=53)$ reports against ketorolac under NSAID and $3(5.66 \%, n=53)$ reports against paracetamol under antipyretic/analgesic were found (Table 1). Under the class iron supplement, ferric carboxymaltose was accounted for $2(3.77 \%$, $\mathrm{n}=53$ ) reports (Table 1$)$. One $(1.89 \%, \mathrm{n}=53)$ report was recorded against allopuronol and another one (1.89, $\mathrm{n}=53)$ report against phenytoin was found (Table 1). Total 16 severe ADRs were found where 7 reactions (consist of 3 SJS and 4 TEN) against cefuroxime; 5 reactions (consist of 3 SJS and 2 TEN) against ceftriaxone, 3 reactions (consist of 3 SJS) against co-trimoxazole and 1 reactions (consists of 1 TEN) against allopuronol was recorded (Table 1).

Table 1: Reported adverse drug reactions and the consequences of severe ADRs.

\begin{tabular}{|c|c|c|c|c|c|c|c|}
\hline $\begin{array}{l}\text { Suspected } \\
\text { drugs of } \\
\text { ADRs }\end{array}$ & $\begin{array}{l}\text { Therapeutic } \\
\text { class of } \\
\text { suspected } \\
\text { drugs }\end{array}$ & $\begin{array}{l}\text { Numbe } \\
r \text { of } \\
\text { ADR } \\
\text { reports }\end{array}$ & $\begin{array}{l}\text { Total } \\
\text { number } \\
\text { of ADR } \\
\text { reports }\end{array}$ & $\begin{array}{l}\text { Total } \\
\text { reactions/ } \\
\text { therapeuti } \\
\text { c class }\end{array}$ & $\begin{array}{l}\% \text { of } \\
\text { reactions/ } \\
\text { therapeuti } \\
\text { c class }(\%) \\
(n=53)\end{array}$ & $\begin{array}{l}\text { Numbe } \\
\text { r of } \\
\text { severe } \\
\text { ADR } \\
\text { reports }\end{array}$ & $\begin{array}{l}\text { Consequences } \\
\text { of severe ADR } \\
\text { with number }\end{array}$ \\
\hline Cefuroxime & \multirow{5}{*}{ Antibiotic } & 17 & \multirow{5}{*}{$53(\mathrm{n})$} & \multirow{5}{*}{43} & \multirow{5}{*}{81.13} & 7 & $\begin{array}{l}\text { SJS (3); TEN } \\
(4)\end{array}$ \\
\hline Ceftriaxone & & 9 & & & & 5 & $\begin{array}{l}\text { SJS (3); TEN } \\
(2)\end{array}$ \\
\hline Meropenem & & 7 & & & & & \\
\hline Ciprofloxacin & & 5 & & & & & \\
\hline Levofloxacin & & 2 & & & & & \\
\hline
\end{tabular}


Early Event Detection and Discontinuation of the Culprit Drug Increases the Rate of Survival in Severe Cutaneous Adverse Drug Reactions: A Multi-Center Study in Bangladesh

\begin{tabular}{|c|c|c|c|c|c|c|}
\hline $\begin{array}{l}\text { Co- } \\
\text { trimoxazole }\end{array}$ & & 2 & & & 3 & SJS (3) \\
\hline Rifaximine & & 1 & & & & \\
\hline Ketorolac & NSAID* & 3 & 3 & 5.66 & & \\
\hline Paracetamol & $\begin{array}{l}\text { Antipyretic } \\
\text { and } \\
\text { Analgesic }\end{array}$ & 3 & 3 & 5.66 & & \\
\hline $\begin{array}{l}\text { Ferric } \\
\text { carboxymaltos } \\
\text { e }\end{array}$ & $\begin{array}{l}\text { Iron } \\
\text { supplement }\end{array}$ & 2 & 2 & 3.77 & & \\
\hline Allopurinol & $\mathrm{XOI}^{*}$ & 1 & 1 & 1.89 & 1 & TEN (1) \\
\hline Phenytoin & $\begin{array}{l}\text { Anticonvulsa } \\
\mathrm{nt}\end{array}$ & 1 & 1 & 1.89 & & \\
\hline
\end{tabular}

NSAID*: Non-steroidal anti inflammatory drug

XOI*: Xanthine oxidase inhibitor

Among the total 53 ADRs, 16 (30.19\%, n=53) (Table 2) reactions were considered as severe ADRs where victims were suffered from serious SJS and TEN. Among those 16 victims (each reaction for each victim), $9(56.25 \%, \mathrm{n}=16)$ victims were survived by treatment after the serious medical conditions (SJS and TEN) and $7(43.75 \%, n=16)$ victims died under treatment (Table 2).

Table 2: Survivals and deaths of the adverse drug events

\begin{tabular}{|c|c|c|l|l|l|}
\hline $\begin{array}{l}\text { Number of } \\
\text { severe ADR } \\
\text { reports }\end{array}$ & $\begin{array}{l}\text { Percentage of } \\
\text { severe ADR } \\
\text { reports }(\mathbf{n = 5 3 )}\end{array}$ & $\begin{array}{l}\text { Number of } \\
\text { survivals after } \\
\text { severe ADR }\end{array}$ & $\begin{array}{l}\text { Percentage } \\
\text { of survivals } \\
\text { after severe } \\
\text { ADR }(\mathbf{n = 1 6})\end{array}$ & $\begin{array}{l}\text { Number of } \\
\text { death after } \\
\text { ADR }\end{array}$ & $\begin{array}{l}\text { Percentage of } \\
\text { death after ADR } \\
(\mathbf{n}=\mathbf{1 6})\end{array}$ \\
\hline 16 & 30.19 & 9 & 56.25 & 7 & 43.75 \\
\hline
\end{tabular}

Among the 16 victims with severe ADRs, 11 victims' events were detected within first 48 hours of the event and there $8(72.73 \%, \mathrm{n}=11)$ victims survived after the treatment (3 victims died), and 5 victims' events were detected after the first 48 hours of the events and their survival rate was just $20 \%$ (1 survived, $n=5$ ) (4 victims died) (Table 3).
Discontinuation of the suspected culprit drug was successfully done within first 48 hours of detection of the events in 9 victims and their survival rate was $77.77 \%$ (7 survivals; $n=9$ ) (2 victims died) (Table 3 ). On the other hand, only $2(28.57 \%, n=7)(5$ victims died) victims were survived when discontinuation of the culprit drug was done after the first 48 hours of the event-detection (Table 3).

Table 3: Survivals with event detection and discontinuation of the culprit drug

\begin{tabular}{|c|c|c|c|c|c|c|c|c|}
\hline $\begin{array}{l}\text { Number of } \\
\text { severe ADR } \\
\text { reports (n) }\end{array}$ & $\begin{array}{r}\text { Numbe } \\
\text { detected } \\
48 \text { houl }\end{array}$ & $\begin{array}{l}\text { f event } \\
\text { thin first } \\
(n=16)\end{array}$ & $\begin{array}{r}\text { Number } \\
\text { detected } \\
48 \text { hour }\end{array}$ & $\begin{array}{l}\text { of event } \\
\text { fter first } \\
(n=16)\end{array}$ & $\begin{array}{r}\text { Disconti } \\
\text { the cul } \\
\text { happen } \\
\text { first } 4 \\
\text { (n }\end{array}$ & $\begin{array}{l}\text { lation of } \\
\text { it drug } \\
\text { I within } \\
\text { hours } \\
\text { 6) }\end{array}$ & $\begin{array}{r}\text { Disconti } \\
\text { culprit d } \\
\text { after } \mathbf{f}\end{array}$ & $\begin{array}{l}\text { tion of the } \\
\text { happened } \\
48 \text { hours } \\
6 \text { ) }\end{array}$ \\
\hline \multirow[t]{3}{*}{16} & \multicolumn{2}{|c|}{11} & \multicolumn{2}{|c|}{5} & \multicolumn{2}{|c|}{9} & \multicolumn{2}{|c|}{7} \\
\hline & Survival & $\begin{array}{c}\% \text { of } \\
\text { survival } \\
(n=11)\end{array}$ & Survival & $\begin{array}{c}\% \text { of } \\
\text { survival } \\
(n=5)\end{array}$ & Survival & $\begin{array}{c}\% \text { of } \\
\text { survival } \\
(n=9)\end{array}$ & Survival & $\begin{array}{c}\% \text { of } \\
\text { survival } \\
(n=7)\end{array}$ \\
\hline & 8 & 72.73 & 1 & 20 & 7 & 77.77 & 2 & 28.57 \\
\hline
\end{tabular}

\section{Discussion}

Currently, ADRs are the burning topic of the major public health interests all over the world and unexpectedly, preventable disease conditions ultimately result in deaths due to ADRs (Mouton et al. 2014). A study suggested that 5-10\% patients are victimized due to ADRs during their admission time, at the time of admission and even at discharge time 
(Coleman et al. 2016). A Swedish population-based study mentioned that ADRs are accounted for $3 \%$ of all deaths and this makes its position at seven among the most common causes of deaths (Wester et al. 2008). Another study in South Africa found that $2.9 \%$ of all deaths among the hospitalized patients are due to ADRs (Mouton et al. 2014).

Hypersensitivity reaction to medications is an unpredictable immune-mediated response to ingested drugs and these reaction ranges from mild type to severe life-threatening events (Teo et al. 2016). The impact of a severe ADR may persist for a long time in victim's life as sequelae of the event and sometimes causes permanent damage of one or more organs. Study found that $6.7 \%$ of all adverse drug reactions in hospitalized patients are severe ADRs and among these events, $0.32 \%$ is fatal events (Lazarou et al. 1998; Teo et al. 2016). Globally, the most frequently reported SCADRs are SJS, TEN, AGEP and drug reaction with eosinophilia and systemic symptoms (DRESS). A review article estimated that globally, SJS and TEN is occurred in 1 to 6 persons and in 0.4 to 1.2 persons per million populations in a year, respectively. DRESS is found in 1 person per $1,000-10,000$ populations in a year and AGEP is observed in 1 to 5 persons per million populations in a year (Cacoub et al. 2011; Chowdhury et al. 2016). Multiple studies showed that SCADRSs are mostly occurred in 21 to 40 yearsaged populations with a prevalence range from 15 to $30 \%$, and most frequent in females than males (Patel et al. 2008; Sushma et al. 2005; Khondker et al. 2014).

Worldwide, most of the ADRs are recorded against a list of culprit drugs like, antiplatelets, anticoagulants, cytotoxics, immunosuppressants, diuretics, antidiabetics and antibiotics (Coleman et al. 2016). Carbamazepine (22\%), Phenytoin (16\%), Phenobarbitals (14\%), Ceftriaxone (6\%), Levofloxacin (4\%) and Fluconazole $(2 \%)$ is accounted for most of the SCADRs found in a study in Bangladesh (Chowdhury et al. 2016). An one year long study in Bangladesh showed that among the SCADRs during that time, $46 \%$ cases are SJS, $28 \%$ cases are TEN, $16 \%$ cases are DRESS and $10 \%$ cases are AGEP recorded (Chowdhury et al. 2016).

In our study, we found that antibiotics are responsible for highest $81.13 \%$ (43 out of 53 reactions) cases of total ADRs during the study period and consist of SCADRs ( 9 cases of SJS and 6 cases of TEN). A total 16 cases of SCADRs $(30.19 \%, n=53)$ were recorded in our study where $9(56.25 \%)$ victims were survived after treatment and 7 victims died under treatment mostly, due to sepsis and hospital acquired pneumonia. Interestingly in this study, when ADEs were detected with in the first 48 hours of the initiation of the event at home or in the healthcare setups in 11 victims, they reported soon to the nearest physician about the event and came under necessary treatment at the early stage of the reaction and survived (8 out of $11,72.73 \%$ ), remarkably. Similarly, those victims $(9, \mathrm{n}=16)$ came under the monitoring of physicians or reported to any healthcare professional without any delay after feeling something worse, physically or any unusual feeling to drug treatment or any visual abnormality in the skin structure, their events were detected early as an SCADR and suspected culprit drugs were stopped upon suggestions, rapidly. As a result, when their culprit drugs were discontinued at an early stage (before 48 hours) of the event, their survival chances raised and finally, survived $(77.77 \%)$. On the other hand, events detection as well as prompt withdrawal of the culprit drugs was delayed (after first 48 hours) in those victims, most of them died under treatment (4 victims and 5 victims, respectively). A Clinicoepidemiological Study showed that identification of the severe drug reaction event and early discontinuation of the suspected drug can improve the prognosis of SCADRs (Sasidharanpillai et al. 2015). Multiple studies found that early recognition of the ADE with the suspected culprit drug responsible for the reaction and prompt stopping of this drug is a life-saving approach at the emergency (Anjaneyan et al. 2013; Randhawa et al. 2018). Specific clinical studies on SCADRs mentioned that fast detection of the suspected drug and early withdrawal of that drug is very effective especially, in SJS and TEN for saving the patient from life-threatening dangerous drug-reactions (Harr et al. 2010; Sharma et al. 2018).

So, from this study we can assume that both early detection of ADEs and prompt stopping of the culprit drugs within the first 48 hours after initiation or observation of the reactions create a tremendous scope to take the victims rapidly under the necessary life-saving treatments, and this approach significantly increase the rate of survival among the SCADRsvictims.

\section{Conclusion}

SCADRs are serious typed unusual responses mostly due to drugs and globally, mortality rate because of these SCADRs is alarming. Peoples are being experienced with SJS and TEN like life-threatening events due to the drugs mostly they receive for completely different treatment purposes. Even in hospitalized patients, use of certain drugs cause SCADRs in admitted patients and results in extended hospitalization time, increased mortality rate and temporary or permanent organ damages as sequelae. In this study, we found that early detection of an 
SCADR event and prompt discontinuation of the suspected culprit drug responsible for that event, can increase the chance of survival among the victims and reduce the mortality rate, significantly.

\section{Conflict of interest:}

No conflict of interests declared.

\section{Acknowledgement}

Authors are grateful to all the participated hospitals and their pharmacovigilance-focal point persons in this study for their great supports and time to time cooperation.

\section{References}

1. Anjaneyan, G., Gupta, R. and Vora, R. (2013). Clinical Study of Adverse Cutaneous Drug Reactions at a Rural Based Tertiary Care Centre in Gujarat. National Journal of Physiology, Pharmacy \& Pharmacology, 3(2): 129-136.

2. Aronson, J.K. and Ferner, R.E. (2005). Clarification of terminology in drug safety. Drug Saf. 28:851-870.

3. Buajordet, I., Ebbesen, J., Erikssen, J., Brørs, O., Hilberg, T. (2001). Fatal adverse drug events: the paradox of drug treatment. J Intern Med, 250:327-341.

4. Cacoub, P., Musette, P., Descamps, V., Meyer, O., Speirs, C., Finzi, L. and Roujeau, J.C. (2011). The DRESS syndrome: A literature review. Am J Med, 124(7):588-597.

5. Chowdhury, M.N.G., Hoque, M.E., Khan, M.A.L. and Khan, M,S,I. (2016). Severe Cutaneous Adverse Drug Reactions in Bangladesh: A Review in a Tertiary Level Hospital. JAFMC Bangladesh, Vol 12, No 2.

6. Coleman, J. J. and Pontefract, S. K. (2016). Adverse drug reactions, Vol 16, No 5: 481-485.

7. Davies, E.C., Green, C.F., Taylor, S., Williamson, P.R. Mottram, D.R., Pirmohamed, M. (2009). Adverse drug reactions in hospital in-patients: a prospective analysis of 3695 patient-episodes. PLoS ONE, 4:e4439.

8. Ebbesen, J., Buajordet, I., Erikssen, J., Brørs, O., Hilberg, T., Svaar, H., Sandvik, L. (2001). Drug-related deaths in a department of internal medicine. Arch Intern Med, 161:2317-2323.

9. Harr, T. and French, L. E. (2010). Toxic epidermal necrolysis and Stevens-Johnson syndrome. Orphanet Journal of Rare Diseases, 5:29

10. Juntti-Patinen, L., Neuvonen, P.J. (2002). Drug-related deaths in a university central hospital. Eur J Clin Pharmacol, 58:479-482.

11. Khondker, L. and Khan, M.S.I. (2014). Clinical profile of cutaneous drug reactions. Journal of Pakistan Association of Dermatologists, 24(2):160-163
12. Kohn. L.T., Corrigan, J.M., Donaldson, M.S. (2000). To err is human: building a safer health system. Washington DC: National Academy Press

13. Lazarou, J., Pomeranz, B.H., Corey, P.N. (1998). Incidence of adverse drug reactions in hospitalized patients: a metaanalysis of prospective studies, JAMA 279: $1200-1205$.

14. Mehta, U., Durrheim, D.N., Blockman, M., Kredo, T., Gounden, R., Barnes, K.I. (2008). Adverse drug reactions in adult medical inpatients in a South African hospital serving a community with a high HIV/AIDS prevalence: prospective observational study. Br J Clin Pharmacol, 65:396-406.

15. Mouton, J.P., Mehta, U., Parrish, A.G., Wilson, D. P.K., Stewart, A., Njuguna, C. W., Kramer, N., Maartens, G., Blockman, M. and Cohen, K. (2014). Mortality from adverse drug reactions in adult medical inpatients at four hospitals in South Africa: A cross-sectional survey. Br J Clin Pharmacol, 80:818-826.

16. Patel, R.M. and Marfatia, Y.S. (2008). Clinical Study of cutaneous drug reaction in 200 patients. Indian J Dermatol Venereol Leprol, 74(4):430.

17. Raksha, M.P., Marfatia, Y.S. (2008). Clinical study of cutaneous drug eruptions in 200 patients. Indian J Dermatol venereal Leprol, 74(1):80.

18. Randhawa, A. and Wylie, G. (2018). A case of an acute cutaneous drug reaction with hydroxychloroquine. Scottish Medical Journal, 63(3): 91-94.

19. Sasidharanpillai, S., Riyaz, N., Khader, A., Rajan, U., Binitha, M.P. and Sureshan, D.N. (2015). Severe Cutaneous Adverse Drug Reactions: A Clinicoepidemiological Study. Indian J Dermatol, 60(1): 102.

20. Sharma, R., Dogra, N. and Dogra, D. (2018). A Clinical Study of Severe Cutaneous Adverse Drug Reactions and Role of Corticosteroids in their Management. Indian Journal of Drugs in Dermatology, 3(1): 20-23

21. Sushma, M., Noel, M.V., Ritika, M.C., James, J. and Guido, S. (2005). Cutaneous adverse drug reactions: a 9-year study from a South Indian Hospital. Pharmacology and Drug Safety, 14(8):567-570.

22. Teo, Y.X. and Walsh, S.A. (2016). Severe adverse drug reactions. Clinical Medicine, 16(1): 79-83.

23. Wester, K., Jönsson, A.K., Spigset, O., Druid, H., Hägg, S (2008). Incidence of fatal adverse drug reactions: a population based study. Br J Clin Pharmacol, 65: 573-579.

24. World Health Organization. (2002). The importance of pharmacovigilance. Geneva: World Health Organization.

25. World Health Organization. (2003). SAFETY OF MEDICINES, A GUIDE TO DETECTING AND REPORTING ADVERSE DRUG REACTIONS. Ministry of Health, CIMed. 